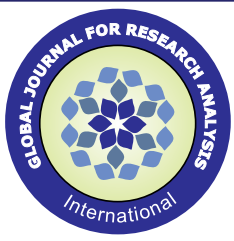

Bhatt Payal*

Joshi Mauli

Inaniya Kailash

\section{Chaudhari Sanjay}

\title{
STUDY OF PLATELET VOLUME INDICES IN PATIENTS OF CORONARY ARTERY
} DISEASE

\section{ABSTRACT}

Background: Various relations have been found out regarding the role of platelets in thrombosis and coronary heart disease. This study is an earnest attempt to delineate the relations between the various platelet volume indices (PVI) and their role in coronary heart disease. Method: During the study period of April 2014 to March 2015 , total 180 subjects were studied. Out of them 120 were cases and 60 were controls. The cases of coronary artery disease were divided in to two groups A and B, according to their treatment. Group A included 60 patients with acute coronary syndromes, mainly AMI and UA with medical treatment. Group B included 60 patients with any percutaneous coronary interventions (PCI) for previous ischemic event. Group $C$ included 60 healthy individuals from health check-up unit. A brief and relevant clinical history and laboratory investigations will be taken on the prepared Performa for the subjects. The EDTA and plain samples of 180 subjects were processed in the Central Diagnostic Laboratory. Results: The present study showed higher PVI in the group A and group B when compared to the control group. MPV, PDW and P-LCR were significantly reduced after treatment in both groups A and B. The mortality was more in those with higher PVI. Conclusion: Coronary artery disease is associated with significant morbidity and mortality. Platelet volume indices in histograms are easily generated by automated cell counter. Thus, by assessment of it we can predict an impending coronary event. We can prevent reinfarction by monitoring of it. The risk of acute coronary event is also decreased after treatment.

\section{KEYWORDS : Platelet Volume Indices, Coronary Artery Disease}

\section{BACKGROUND}

Atherosclerosis is the major cause of vascular occlusive disorders such as coronary artery disease, stroke, and peripheral arterial disease. Platelets have an important role in the initiation of atherosclerotic lesions, rupture and subsequent complications. Of all the developing nations, India is undergoing the most rapid epidemiologic transition from communicable to non-communicable diseases and at the third stage of the transition characterized by high burden of atherothrombotic dominated non-communicable diseases. ${ }^{1}$ Platelet activity is studied by platelet volume indices (PVI). Platelet indices or platelet volume parameters mainly include plateletcrit (PCT), mean platelet volume (MPV), platelet distribution width (PDW) and platelet large cell ratio (P-LCR) ${ }^{2}$. Mean platelet volume (MPV) is a machinecalculated measurement of the average size of platelets found in blood. High MPV associates with a variety of established risk factors, cardio- and cerebrovascular disorders, and lowgrade inflammatory conditions prone to arterial and venous thrombosis ${ }^{3}$. The platelet distribution width (PDW) indicates the platelet distribution width measured at $20 \%$ relative height of the total height of the curve. An increased PDW is an indication for the anisocytosis of platelets 10. The P-LCR indicates the percentage of large platelets with a volume $>12 \mathrm{fl}$.

\section{AIMS AND OBJECTIVES}

1. To study the changes in platelet count and platelet volume indices in patients of coronary artery disease in two study groups.

2. To compare those changes with healthy controls to establish clinico-pathological correlation.

3. To study the association between platelet volume indices, platelet count and acute coronary syndromes and to assess their usefulness in predicting coronary events and assessing their severity.

4. To study the changes in platelet volume indices after treatment and compare them with pre-treatment platelet volume indices.
MATERIAL AND METHODS

This is an observational study carried out at Central Diagnostic Laboratory of Shree Krishna Hospital, a rural tertiary care hospital of Anand district of Gujarat state. The study period is of one year from April 2014 to March 2015. The study specimen included three groups of the patients admitted to Shree Krishna Hospital.

Group A: 60 Patients admitted with acute coronary syndrome (ACS), which includes acute myocardial infarction (AMI) and unstable angina (UA).

Group B: 60 Patients admitted for any percutaneous coronary interventions (PCI) like coronary artery bypass graft (CABG) and coronary stents for previous ischemic event.

Group C: 60 Healthy controls from health check-up unit whose age is greater than 25 years with no history of coronary artery disease or any other heart disease and with normal electrocardiogram (ECG).

Inclusion Criteria:

Patients with acute myocardial infarction and unstable angina and those for any percutaneous coronary interventions (PCI) like coronary artery bypass graft and coronary stents for previous ischemic event.

\section{Exclusion Criteria:}

Patients with functional platelet disorders, aplastic anaemia, ITP, blood dyscrasias, sepsis, with recent history of major operations and trauma (within 6 weeks), who are receiving drugs which can cause thrombocytopenia., recent dengue, malaria and other infections which will cause thrombocytopenia. Histograms with flagged PVI are excluded.

\section{RESULTS}

Significant difference was seen in the distribution of mean 
platelet count among three groups as p value- 0.003 . Mean of platelet count of group $\mathrm{C}$ was higher compared to groups $\mathrm{A}$ and $\mathrm{B}$.

Table 1. Comparison Of Mean Of Platelet Count Of Day 1 In Groups A, B And C

\begin{tabular}{|l|l|}
\hline Groups & Mean platelet count \pm SD \\
\hline Group A & $272.33 \times 103 / \mu \mathrm{l} \pm 100.54$ \\
\hline Group B & $279.37 \times 103 / \mu \mathrm{l} \pm 99.03$ \\
\hline Group C & $325.20 \times 103 / \mu \mathrm{l} \pm 64.51$ \\
\hline
\end{tabular}

Significant difference was seen in the distribution of MPV between three groups as $p$ value- $<0.001$. Significant difference was also seen in the MPV among groups A and B as $\mathrm{p}$ value $<0.05$. In group B MPV was higher compared to group A. Significant difference was seen in the distribution of MPV among groups $\mathrm{A}$ and $\mathrm{C}$ and groups $\mathrm{B}$ and $\mathrm{C}$, because in both of them p value- $<0.05$.

Table 2. Comparison Of Mean Of MPV Of Day 1 In Groups A, B And C

\begin{tabular}{|l|l|}
\hline Groups & Mean of MPV \pm SD \\
\hline Group A & $12.34 \pm 1.85$ \\
\hline Group B & $13.49 \pm 2.09$ \\
\hline Group C & $9.41 \pm 0.76$ \\
\hline
\end{tabular}

Significant difference was seen in the distribution of PDW between three groups as $p$ value $<0.001$. Mean of PDW of group $\mathrm{C}$ was lower compared to groups $\mathrm{A}$ and $\mathrm{B}$.

Table 3. Comparison Of Mean Of PDW Of Day 1 In Groups A, B and C

\begin{tabular}{|l|l|}
\hline Groups & Mean of PDW \\
\hline Group A & $14.53 \pm 1.78$ \\
\hline Group B & $14.75 \pm 1.41$ \\
\hline Group C & $9.60 \pm 0.64$ \\
\hline
\end{tabular}

Significant difference was seen in the distribution of P-LCR between three groups as $p$ value $<0.001$. Mean of P-LCR of group $\mathrm{C}$ was lower compared to groups A and B. Significant difference was also seen in the P-LCR among groups A and B as $p$ value $<0.05$. In group B P-LCR was higher compared to group A. Significant difference was seen in the distribution of P-LCR among groups $A$ and $C$ and groups $B$ and $C$, because in both of them $p$ value $<0.05$.

Table 4. Comparison Of Mean Of P-lcr Of Day 1 In Groups A, B and C

\begin{tabular}{|l|l|}
\hline Groups & Mean of P-LCR \pm SD \\
\hline Group A & $32.00 \pm 3.60$ \\
\hline Group B & $33.30 \pm 3.17$ \\
\hline Group C & $21.42 \pm 3.25$ \\
\hline
\end{tabular}

For group $\mathrm{A}, \mathrm{P}$ value for pre-treatment and post-treatment mean platelet count comparison - 0.077. P value for pretreatment and post-treatment MPV comparison - < 0. 001.P value for pre-treatment and post-treatment PDW comparison $<0.001$.P value for pre-treatment and post-treatment PLCR comparison- $<0.001$.No significant difference was seen in the platelet count after treatment. But significant difference was seen in MPV, PDW and P-LCR after treatment in group A patients.

Table 5. Comparison Of Pre-treatment And Post Treatment PC, MPV, PDW And P-LCR Of Group A

\begin{tabular}{|l|l|l|l|}
\hline & $\begin{array}{l}\text { Pre-Treatment } \\
\text { (Day 1) }\end{array}$ & $\begin{array}{l}\text { Post Treatment } \\
\text { (Day 7) }\end{array}$ & P Value \\
\hline Mean PC & 272.33 & 286.68 & 0.003 \\
\hline Mean MPV & 12.34 & 11.27 & $<0.001$ \\
\hline Mean PDW & 14.53 & 13.15 & $<0.001$ \\
\hline Mean P-LCR & 32.00 & 29.56 & $<0.001$ \\
\hline
\end{tabular}

$\mathrm{P}$ value is $<0.05$. Thus, significant difference was seen in PC, MPV, PDW and P-LCR after treatment in group B patients.
Table 6. Comparison Of Pre-treatment And Post Treatment PC, MPV, PDW And P-LCR Of Group A

\begin{tabular}{|l|l|l|}
\hline & Pre-treatment (Day 1) & Post treatment (Day 7) \\
\hline Mean PC & 279.37 & 295.90 \\
\hline Mean MPV & 13.49 & 12.84 \\
\hline Mean PDW & 14.75 & 14.14 \\
\hline Mean P-LCR & 33.30 & 32.00 \\
\hline
\end{tabular}

Table 7. Comparison Of Mortality And Its Significance In For Platelet Count And Platelet Volume Indices In Expired And Survivor Patients Of Groups A And B

\begin{tabular}{|l|l|l|l|l|l|}
\hline & & $\begin{array}{l}\text { Hospital } \\
\text { Mortality }\end{array}$ & Number & Mean & P value \\
\hline 1 & \multirow{2}{*}{ Platelet Count } & Expired & 11 & 278.82 & \multirow{2}{*}{0.918} \\
\cline { 3 - 5 } & & Survivor & 109 & 275.55 & \\
\hline 2 & \multirow{2}{*}{ MPV } & Expired & 11 & 14.26 & 0.022 \\
\cline { 3 - 5 } & & Survivor & 109 & 12.78 & \\
\hline 3 & PDW & Expired & 11 & 16.09 & 0.001 \\
\cline { 3 - 5 } & & Survivor & 109 & 14.49 & \\
\hline 4 & P-LCR & Expired & 11 & 36.76 & $<0.001$ \\
\cline { 3 - 5 } & & Survivor & 109 & 32.23 & \\
\hline
\end{tabular}

Thus, significant changes were present among the platelet volume indices between those who expired during the course in hospital with the survivors. MPV, PDW and P-LCR were higher in expired patients compared to survivors of both groups.

\section{DISCUSSION}

Platelets and their activity have an important role in initiation of atherosclerotic lesions and coronary thrombus formation. According to recent studies, larger platelets are enzymatically and metabolically more active ${ }^{4,5}$ and have a higher potential for thrombosis compared to smaller ones ${ }^{6}$. Some studies showed that a decrease in platelet count (PC) may be characteristic of the pre-thrombotic state in coronary heart disease ${ }^{7}$. In this study, the mean platelet count in the group $A, B$ and $C$ were $272 \times 103,279 \times 103$ and $325 \times 103$, respectively. It is seen that the platelet count (PC) is lower in the patients of AMI and UA i.e. group A compared to healthy controls i.e. group C. The platelet count is also lower in patients who are posted for percutaneous coronary intervention (PCI) i.e. group $\mathrm{B}$ compared to healthy controls i.e. group $\mathrm{C}$. The difference is statistically significant ( $p$ value $<0.05$ ). This is in discordance with the study conducted by Ihara $A$ et al Hiroshima, Japan which showed no change in platelet count in patients of acute myocardial infarction when compared to control population. But there are some other studies which showed low platelet count in subjects with acute coronary syndromes when compared with the control group.

A comparative study by Mathur A et al found that platelet count is decreased in patient with unstable angina. N Mesbah Ardakani et al found that platelet count in unstable angina was significantly lower than chronic stable angina and control group. The present study showed a higher mean platelet volume in the group A and group B (12.34 \pm 1.85 and $13.59 \pm 2.09$, respectively) when compared to the control group which had a mean platelet volume of $9.41 \pm 0.76$. This difference was statistically highly significant ( $p$ value $<0.001$ ). Significant difference was not seen between comparing MPV values of group A and B. Similar results were obtained in several other studies. This finding correlate with the result of other previous studies which had shown MPV increases in unstable angina, and acute myocardial infarction. Examples are studies by O" Brien et al, Cameron et al, Martin et al, Smyth et al, N Mesbah Ardakani et al, Mehmet Birhan Yilmaz et al, M M Khandekar et al, Mathur A et al, L.Pizzulli et al and Anna Butkiewicz et al.

There are several theories to explain the reason of MPV increase in acute coronary syndromes. According to one 
presumption this could be explained by a physiological mechanism controlled in part by the hormone erythropoietin ${ }^{8,9}$ In this study the mean of platelet distribution width was significantly higher in the groups $A$ and $B(14.53 \pm 1.78$ and $14.75 \pm 1.41$, respectively) when compared to controls (9.60 \pm $0.64)$. This difference was statistically highly significant ( $p$ value $<0.001$ ). However significant difference was not seen between comparing PDW values of group A and group B. This finding was similar to results of various other previous studies. Abdullah S et al, T Rechcinski et al, M M Khandekar et al found a noticeable increase of PDW values in unstable angina patients as compared to normal people. Vagdati et $\alpha{ }^{10}$ found that platelet distribution width is a more specific marker of platelet activation since it does not increase due to platelet swelling when EDTA used as an anticoagulant and remarked that combined use of platelet distribution width and mean platelet volume could predict activation of coagulation more efficiently. In the present study the mean of platelet large cell ratio was found to be higher in the groups $A$ and B (32.00 \pm 3.60 and 33.00.05 \pm 3.17 , respectively) when compared with the group C (21.42 \pm 3.25$)$. This difference was statistically highly significant with a $\mathrm{p}$ value $<0.001)$. Abdullah $\mathrm{S}$ et $a \mathrm{l}, \mathrm{T}$ Rechcinski et al, M M Khandekar et al found a noticeable increase of P-LCR values in unstable angina patients as compared to healthy controls. However significant difference was not seen between comparing P-LCR values of group A and $B$. This is an expected result because platelet large cell ratio is just another index of platelet volume and it is increased in conditions with increased mean platelet volume. MPV, PDW and P-LCR were significantly reduced after treatment. This is discordant with the study of M M Khandekar et al ${ }^{11}$. In that study platelet volume indices could be measured on day 7 in only 78 of the 94 patients in group A because six patients died before day 7 and nine patients were discharged. The platelet counts and platelet volume indices values on day 1 and day 7 in group A and group B were not significantly different in the study of M M Khandekar et al. Hence more studies are required in this aspect. In this study, $10.0 \%$ patients of group $A$ and $8.3 \%$ patients of group $B$ had shown mortality. There was no significant difference between platelet counts in expired and survivor patients. But the mortality was more in those with higher platelet indices compared to those with lower values and the values were significant $(\mathrm{P}<0.05)$. This shows that those having higher value of platelet volume indices have a poorer prognosis as per this study. This has been in line with the studies by T. Rechcinski et $\alpha l^{12}$, Slavka et $\alpha{ }^{13}$.

\section{CONCLUSION}

The study proves that platelet volume indices have correlation with coronary artery disease patients because the PVI were within normal range in controls. Coronary artery disease is associated with significant morbidity and mortality. Platelet volume indices in histograms are easily generated by automated cell counter. Thus, by assessment of it we can predict an impending coronary event. We can prevent reinfarction by monitoring of it. We can also predict the risk of acute coronary event after treatment.

\section{REFERENCES}

1. Gupta R., Joshi P., Mohan V. Epidemiology and causation of coronary heart disease and stroke in India. Heart. 2008; 94:16-26.

2. Thayse V., Josiane P. Platelet indices: laboratory and clinical applications: Revista brasiliera de hematologia e hemoterapia-2011;33(2):164.

3. Yuri Gasparyan A, Ayvazyan L, P. Mikhailidis D, D. Kitas G. Mean Platelet Volume: A Link Between Thrombosis and Inflammation: Current Pharmaceutical Design. 2011;17(1):47-58.

4. Corash L, Tan H, Gralnick HR. Heterogeneity of human whole blood platelet subpopulation. Relationship between byoyant density, cell volume and ultrastructure. Blood 1977; 49:71 - 87.

5. Erusalimsky JD, Martin JF. The regulation of megakaryocyte polyploidization and its implication for coronary artery occlusion. Cur J clin Invest. 1993; 23:1-9.

6. Karpatkin. S. Biochemical and clinical aspects of megathrombocytes.Annals of the New York Acadmy of science. 1972; 201:262-279

7. Angelillo-Scherrer A, de Frutos P, Aparicio C, et al. Deficiency orinhibition of Gas6 causes platelet dysfunction and protects mice against thrombosis. Nat Med 2001; 7:215-221.

8. Bain B, Lewis S, Dacie J. Dacie and Lewis practical haematology.
[Edinburgh]: Elsevier Churchill Livingstone; 2012.

9. Gulati GL, Hyun BH, Ashton JK. Advances of the past decade in automated haematology. Am J Clin Pathol 1992; 4 (suppl. 1): sl 1-21.

10. Vagdatli E Gounari E, Platelet distribution width: a simple, practical and specific marker of activation of coagulation: Hippokratia. 2010 Jan-Mar; 14(1): 28-32.

11. M M Khandekar, A S Khurana, S D Deshmukh, A L Kakrani, A D Katdare,A K Inamdar, Platelet volume indices in patients with coronary artery disease and acute myocardial infarction:an Indian scenario. Journal of Clinical Pathology2006; 59:146-149

12. Rechcinski T,Jasinska A,forys j,Krzeminska Pakula m,Wierzbowska-Drabik k,Plewka M Cardiol j 2013:20(5):491-8 prognostic value of platelet indices after acute myocardial infarction treated with primary percutaneous coronary intervention. 2013:20(5):491-8

13. Slavka G, Thomas P, Helmuth H, Stefan G, Claudia M, Oswald F. Mean platelet volume may represent a predictive parameter or overall vascular mortality and ischemic heart disease Arteriosclerosis Thrombosis and Vascular biology 2011; 31:1215-1218 